\title{
CARACTERÍSTICAS FÍSICAS E GERMINAÇÃO DE SEMENTES DE Dyckia goehringii Gross \& Rauh (BROMELIACEAE) SOB DIFERENTES TEMPERATURAS ${ }^{1}$
}

\author{
Edson Ferreira Duarte ${ }^{2}$, Iraídes Fernandes Carneiro ${ }^{3}$, Natan Fontoura da Silva ${ }^{3}$, Noga Neve Ribeiro Guimarães ${ }^{3}$
}

\begin{abstract}
PHYSICAL CHARACTERISTICS AND GERMINATION OF Dyckia goehringii Gross \& Rauh (BROMELIACEAE) SEEDS UNDER DIFFERENT TEMPERATURES

Dyckia goehringii is a bromeliad native from Cerrado (Brazilian savannah). Despite its high ornamental value, because of the silvery appearance of its leaves, it is not yet commercialized due to lack of information on its conservation and agronomic employment. The present investigation aimed to appraise the physical and physiological performance of seeds, during the imbibition and germination period, under several temperatures, as well as to establish temperature parameters for germination tests. The moisture content and the fresh and dry mass content of one hundred seeds were determined. The imbibition capacity, germination and vigour of seeds and seedlings of large and small seeds were observed under temperatures of $20^{\circ} \mathrm{C}, 25^{\circ} \mathrm{C}, 30^{\circ} \mathrm{C}$, and $35^{\circ} \mathrm{C}$. The results showed that there are no obstructions to water absorption and that this feature is influenced by seeds size. The best vigour and germination rate were observed to large seeds, which produce more vigorous seedlings than small seeds, mainly at $30^{\circ} \mathrm{C}$, and germination tests should be carried out on the 7 th and 14 th days after sowing.
\end{abstract}

KEY-WORDS: Dyckia goehringii; seed vigour and size; imbibition.

\section{INTRODUÇÃO}

A família Bromeliaceae é constituída por três subfamílias: Bromelioideae, Tillandsioideae e Pitcairnioideae. Nesta última, está o gênero Dyckia, ocorrente na América do Sul, especialmente no Brasil Central, composto por, aproximadamente, 121 espécies (Leme \& Marigo 1993).

Dyckia goehringii (Gross \& Rauh) é uma espécie do Cerrado, provavelmente endêmica, encontrada na Serra do Caiapó, no município de Portelândia

\section{RESUMO}

Dyckia goehringii Gross \& Rauh é uma bromélia nativa do Cerrado, de alto potencial ornamental, devido à coloração prateada de suas folhas, e que ainda não foi explorada comercialmente, exigindo estudos para a sua conservação e aproveitamento agronômico. O presente estudo objetivou avaliar as características físicas e o comportamento fisiológico de sementes de $D$. goehringii, durante a embebição e a germinação, sob diferentes temperaturas, bem como determinar parâmetros de temperatura e de tempo para a realização de testes de germinação. Foram determinados os teores de água e massa de matéria fresca e seca de 100 sementes e avaliados a capacidade de embebição, germinação e vigor de sementes e de plântulas de sementes pequenas e grandes, sob temperaturas de $20^{\circ} \mathrm{C}, 25^{\circ} \mathrm{C}, 30^{\circ} \mathrm{C}$ e $35^{\circ} \mathrm{C}$. Os resultados indicam que as sementes não apresentam impedimento à absorção de água e que esta é influenciada pelo tamanho das sementes. Sementes grandes apresentam maior germinação e vigor, originando plântulas mais vigorosas do que sementes pequenas, expressando melhor o seu potencial fisiológico à temperatura de $30^{\circ} \mathrm{C}$. As avaliações do teste de germinação devem ser realizadas no sétimo e décimo quarto dias após a semeadura.

PALAVRAS-CHAVE: Dyckia goehringii; vigor e tamanho de semente; embebição.

(GO), tendo sido descrita, em 1991, por Werner Rauh e Elvira Gross (Braum \& Pereira 2004).

O Cerrado vem sofrendo redução em sua superfície, à taxa de, aproximadamente, 3,00\% ao ano (Felfili et al. 2004), resultando em perdas de populações e/ou espécies, neste bioma. Fato semelhante já foi observado em áreas de Mata Atlântica, com o desaparecimento de populações de cerca de 20 espécies de Bromeliaceae (Siqueira Filho \& Tabareli 2006).

D. goehringii possui elevado potencial ornamental, devido, principalmente, à pubescência densa

1. Trabalho recebido em abr./2009 e aceito para publicação em nov./2010 (nº registro: PAT 6037/ DOI: 10.5216/pat.v40i4.6037).

2. Universidade Federal do Recôncavo da Bahia, Centro de Ciências Agrárias, Ambientais e Biológicas, Cruz das Almas, BA, Brasil.E-mail: duarteef@ufrb.edu.br.

3. Universidade Federal de Goiás, Escola de Agronomia e Engenharia de Alimentos, Goiânia, GO, Brasil. E-mails: iraidesfc@hotmail.com, natan@agro.ufg.br, noga@agro.ufg.br. 
que recobre suas folhas, tornando-a prateada, sendo incluída no Programa Plantas do Futuro, desenvolvido pelos Ministérios do Meio Ambiente, da Agricultura, Pecuária e Abastecimento e pela Embrapa.

As sementes de $D$. goehringii são aladas e dispersas pelo vento e devem ser colhidas logo que as cápsulas iniciam a deiscência (Menescal 1994, Duarte 2007). Apesar da produção de grande quantidade de sementes, pela espécie em estudo, não se conhecem resultados sobre a sua germinação e vigor.

O tamanho das sementes deve ser levado em consideração, quando ocorre sua seleção para germinação, visto que esta é uma característica que pode afetar o vigor (Fenner 1993). Sementes maiores, com maior quantidade de reservas nutritivas, geralmente apresentam vantagens, em relação às pequenas, pois germinam mais rapidamente e são mais vigorosas, promovendo rápido crescimento das raízes (Pollock \& Roos 1972).

Geralmente, as sementes respondem à temperatura para germinarem, sendo necessária a determinação da faixa ótima de temperatura, ou seja, o intervalo de temperatura no qual ocorre a máxima germinação, em menor tempo (Labouriau 1983). A temperatura afeta a velocidade de absorção de água e o metabolismo das reservas necessárias ao desenvolvimento inicial e à sobrevivência das novas plantas (Bewley \& Black 1986, Fenner 1993).

Espécies cultivadas, normalmente, germinam entre $20^{\circ} \mathrm{C}$ e $30^{\circ} \mathrm{C}$ (Marcos Filho 2005), fato que ocorre, também, para espécies nativas de campos rupestres (Gomes \& Fernandes 2002, Abreu \& Garcia 2005). Apesar de serem poucos os trabalhos realizados com germinação de sementes de bromélias, Pinheiro \& Borghetti (2003), trabalhando com Aechmea nudicaulis (L.) Griesebach e Streptocalyx floribundus (Martius ex Schultes F.) Mez, espécies da restinga, verificaram que suas sementes germinam melhor entre $20^{\circ} \mathrm{C}$ e $30^{\circ} \mathrm{C}$. Sementes de Dyckia dystachia Hassler germinam melhor na presença de luz, sob temperatura ambiente, variando de $21^{\circ} \mathrm{C}$ a $30^{\circ} \mathrm{C}$ (Wiesbauer et al. 2007).

Para a germinação de Dyckia tuberosa (Vell.) Beer, fora da faixa ótima, entre $30^{\circ} \mathrm{C}$ e $35^{\circ} \mathrm{C}$, houve maior assincronia no processo germinativo, sem, contudo, reduzir a capacidade germinativa das sementes (Vieira et al. 2007). Pompelli (2006), estudando a germinação de Dyckia encholirioides (Gaud) Mez. var. encholirioides, verificou o retardamento da iniciação da germinação, quando as sementes foram pré-esfriadas. Smith \& Downs (1974) destacam que o conhecimento da temperatura necessária à germinação de sementes de bromélias pode auxiliar no entendimento da distribuição das espécies.

O presente estudo objetivou avaliar as características físicas e o comportamento fisiológico de sementes de $D$. goehringii, durante a embebição e a germinação, sob diferentes temperaturas, bem como determinar parâmetros para a realização de testes de germinação.

\section{MATERIAL E MÉTODOS}

O experimento foi realizado em setembro de 2005, no Laboratório de Análise de Sementes do Setor de Agricultura da Escola de Agronomia e Engenharia de Alimentos da Universidade Federal de Goiás, utilizando-se sementes de Dyckia goehringii, obtidas a partir de frutos fechados, de coloração marrom, coletados em junho de 2005, em plantas de uma população natural, no município de Portelândia (GO).

Os frutos foram mantidos em embalagens semipermeáveis, por duas semanas, e, posteriormente, colocados para secagem à sombra, sobre papel, até que ocorresse deiscência natural, o que aconteceu após duas semanas. A seguir, as sementes foram armazenadas em recipientes plásticos dotados de tampa, à temperatura e luz ambientes, durante três meses.

Verificou-se elevada heterogeneidade no tamanho das sementes, as quais foram separadas em dois lotes, sendo o primeiro composto por sementes pequenas, retidas em peneiras de malha de arame de 1,00 $\mathrm{mm}$, tendo passado por malha de $3,76 \mathrm{~mm}$, formando um lote com sementes de dimensões $>1,00 \mathrm{~mm}$ e $\leq 3,76 \mathrm{~mm}$. Já o segundo lote foi composto por sementes grandes, retidas nas peneiras de malha de arame de $3,76 \mathrm{~mm}$, tendo passado por malha de 5,90 mm, formando um lote com sementes de dimensões $>3,76 \mathrm{~mm}$ e $\leq 5,90 \mathrm{~mm}$. Para a caracterização física, selecionou-se uma amostra de 20 sementes de cada lote, avaliando-se o comprimento, largura e espessura, com auxílio de um paquímetro, tendo-se adotado o eixo embrionário como referência para tomada do comprimento. A largura e a espessura foram medidas, respectivamente, em plano perpendicular e transversal ao do comprimento.

O teor de água na base úmida e a massa de matéria seca média foram determinados pelo método da estufa, a $105 \pm 3^{\circ} \mathrm{C}$ (Silva 1988, Brasil 1992), utilizando-se quatro repetições de 100 sementes. A 
massa de 100 sementes foi obtida pela média de oito repetições (Brasil 1992), utilizando-se uma balança analítica com quatro casas decimais.

Determinaram-se as curvas de absorção de água das sementes, em teste de embebição rápida, colocando-se as sementes diretamente em água, sob quatro temperaturas constantes $\left(20^{\circ} \mathrm{C}, 25^{\circ} \mathrm{C}, 30^{\circ} \mathrm{C}\right.$ e $35^{\circ} \mathrm{C}$ ). Utilizaram-se amostras intactas, obtidas de cada um dos lotes de sementes pequenas e grandes, divididas em quatro repetições de 100 sementes/temperatura, sendo mantidas em recipientes com capacidade de $150 \mathrm{~mL}$, imersas em cerca de $100 \mathrm{~mL}$ de água destilada. As avaliações foram realizadas por meio de pesagens sucessivas das sementes, ao longo do tempo (1 h, 6 h, 12 h, 24 h, 33 h, 52 h, 76 h, 90 h, 114 h e $138 \mathrm{~h}$ ), em balança analítica. A quantidade de água absorvida, nas repetições sob diferentes temperaturas, foi obtida pela fórmula proposta por Cromarty et al. (1985), MU1 (100 - U1) = MU2 (100 - U2), em que $\mathrm{MU}=$ Massa da matéria úmida das sementes (g) e $\mathrm{U}=$ Teor de água das sementes (\%).

Os resultados médios da absorção de água de sementes pequenas e grandes, em cada temperatura, foram expressos em percentagem, sendo apresentada a absorção de água ao longo do tempo.

Para a realização do teste de germinação, sob diferentes temperaturas, foram selecionadas outras amostras intactas, dos lotes de sementes pequenas e grandes, sendo divididas em quatro repetições de 100 sementes/temperatura. As temperaturas utilizadas nos testes de germinação foram constantes $\left(20^{\circ} \mathrm{C}\right.$, $25^{\circ} \mathrm{C}, 30^{\circ} \mathrm{C}$ e $35^{\circ} \mathrm{C}$ ), mantendo-se as sementes em diferentes câmaras germinadoras, sob fotoperíodo de 12 horas de luz. As sementes intactas foram colocadas para germinar em caixas plásticas tipo Gerbox, sobre duas folhas de papel mata-borrão, pré-umedecidas com volume de água destilada 2,5 vezes a massa do papel (Brasil 1992). Adotou-se, para o teste de germinação, o delineamento experimental inteiramente casualizado, em esquema fatorial $2 \times 4$ (tamanho da semente $\mathrm{x}$ temperatura).

Avaliou-se, diariamente, a germinação, a qual foi expressa em percentagem, até que ocorresse a estabilização da maioria das repetições, por três dias consecutivos (Brasil 1992), e calculou-se o índice de velocidade de germinação (IVG), conforme Maguire (1962).

As sementes foram consideradas germinadas quando apresentaram protrusão da bainha cotiledonar (Pereira 1988), sendo apresentadas as curvas de ger- minação acumulada para cada tamanho. Ao final do experimento, avaliou-se o vigor das sementes, através do IVG, e considerou-se a percentagem média da germinação, aos sete dias, como a primeira contagem. Avaliou-se o vigor das plântulas, pelo comprimento da parte aérea e das raízes, além da massa de matéria fresca, conforme Nakagawa (1994).

Os dados da germinação foram transformados em arco-seno $\sqrt{x / 100}$ e submetidos a análise de variância, em delineamento inteiramente casualizado (Santana \& Ranal 2004). As médias das variáveis do vigor foram comparadas pelo teste Student Newman Keuls (SNK), a 5\% de probabilidade (Sampaio 1998). As curvas de absorção de água foram submetidas a análise de regressão, ajustando-se equações representativas dos modelos biológicos (Pimentel-Gomes 2000).

\section{RESULTADOS E DISCUSSÃO}

As sementes apresentaram comprimentos médios de 3,28 $\mathrm{mm}$ e 4,69 $\mathrm{mm}$ e larguras médias de 3,54 $\mathrm{mm}$ e $5,40 \mathrm{~mm}$, para sementes pequenas e grandes, respectivamente. A espessura média foi de cerca de $0,70 \mathrm{~mm}$, tendo ocorrido variação significativa apenas para largura e comprimento médios (Tabela 1). As sementes de D. goehringii são elipsoidais, apresentando desuniformidade na forma e no tamanho, de acordo com sua posição no fruto (Duarte 2007). Esta variação no tamanho e na morfologia das sementes pode ocorrer em decorrência da forma do ovário, das condições com que as plantas-mães cresceram durante a formação da semente e da espécie (Mayer \& Poljakoff-Mayber 1963). A separação das sementes por classe de tamanho deve ser feita para determinação de sua qualidade, com o objetivo de se encontrar a classe ideal para a multiplicação da espécie (Frazão et al. 1983). Os autores citados observaram que sementes de guaraná de maior tamanho apresentaram qualidade fisiológica superior àquelas menores.

As sementes de $D$. goehringii de maior tamanho atingiram, em média, valores três vezes maiores de massa de matéria seca e fresca, quando comparadas àquelas classificadas como pequenas (Tabela 1).

Os teores de água foram semelhantes para ambos os lotes estudados, atingindo cerca de 9\% (Tabela 1), valor considerado adequado para a conservação das sementes ortodoxas, pois, quando estas são desidratadas, seu metabolismo é reduzido a níveis 
Tabela 1. Dimensões, teor de água, massa de matéria seca e fresca de sementes de Dyckia goehringii Gross \& Rauh (Bromeliaceae) (Goiânia, GO, 2005).

\begin{tabular}{|c|c|c|c|}
\hline \multirow{2}{*}{\multicolumn{2}{|c|}{ Variáveis }} & \multicolumn{2}{|c|}{ Sementes } \\
\hline & & Pequenas & Grandes \\
\hline \multirow{3}{*}{ Dimensões $(\mathrm{mm})^{1}$} & Comprimento & $3,28 \pm 0,66 \mathrm{~b}$ & $4,69 \pm 0,54 \mathrm{a}$ \\
\hline & Largura & $3,54 \pm 0,89 \mathrm{~b}$ & $5,40 \pm 0,50 \mathrm{a}$ \\
\hline & Espessura & $0,76 \pm 0,45 \mathrm{a}$ & $0,68 \pm 0,15 \mathrm{a}$ \\
\hline & $9,32 \mathrm{a}$ & $9,48 \mathrm{a}$ \\
\hline \multirow{2}{*}{\multicolumn{2}{|c|}{ Massa de matéria seca de 100 sementes $(\mathrm{g})^{2}$}} & $0,09 \mathrm{~b}$ & $0,26 \mathrm{a}$ \\
\hline & & $0,10 \mathrm{~b}$ & $0,30 \mathrm{a}$ \\
\hline
\end{tabular}

${ }^{1}$ Médias seguidas dos desvios padrões e por letras distintas, nas linhas, diferem entre si, a $5 \%$ de probabilidade, pelo teste SNK.

${ }^{2}$ Médias seguidas por letras distintas, nas linhas, diferem entre si, a 5\% de probabilidade, pelo teste SNK.

mínimos, o que lhes permite sobreviver a estresses ambientais (Castro et al. 2004). Marcos Filho (2005) relata que, para espécies de sementes ortodoxas, os teores de água entre $10 \%$ e $12 \%$ permitem a manutenção da germinação, por um período de seis a oito meses. Já Bewley \& Black (1986) recomendam teores entre $8 \%$ e $9 \%$, para que ocorra restrição à atividade de insetos.

As sementes em estudo não apresentaram restrições à absorção de água, quando imersas diretamente em água, durante o teste de embebição. A absorção de água das sementes de ambos os tamanhos teve sua estabilização após 24 horas do início da embebição, atingindo entre $65 \%$ e $85 \%$ (Figuras 1a e 1b). O comportamento sigmoidal típico para embebição de sementes, descrito por Bewley \& Black (1986), não foi observado para a espécie em estudo, até as 138 horas de acompanhamento. Após
90 horas do início do teste de embebição (período em que ocorreu a protrusão radicular das sementes), não foi verificado um rápido incremento na absorção de água (Figuras 1a e 1b).

Marcos Filho (2005) relata que as partes das sementes embebem-se em velocidades distintas, ocorrendo maior absorção pelo eixo embrionário, onde acontecem intensas divisões celulares. $\mathrm{O}$ volume do eixo embrionário e a composição química dos tecidos de reserva determinam maior ou menor proporção de absorção de água pela semente. Duarte (2007) verificou que o embrião de $D$. goehringii é pequeno, com cerca de $1,00 \mathrm{~mm}$ de comprimento, ficando envolto por um endosperma amiláceo, que ocupa mais de $4 / 5$ da semente. Tais aspectos também contribuem para a lenta embebição na espécie estudada e podem contribuir para a ocorrência de desuniformidade no processo de germinação, com
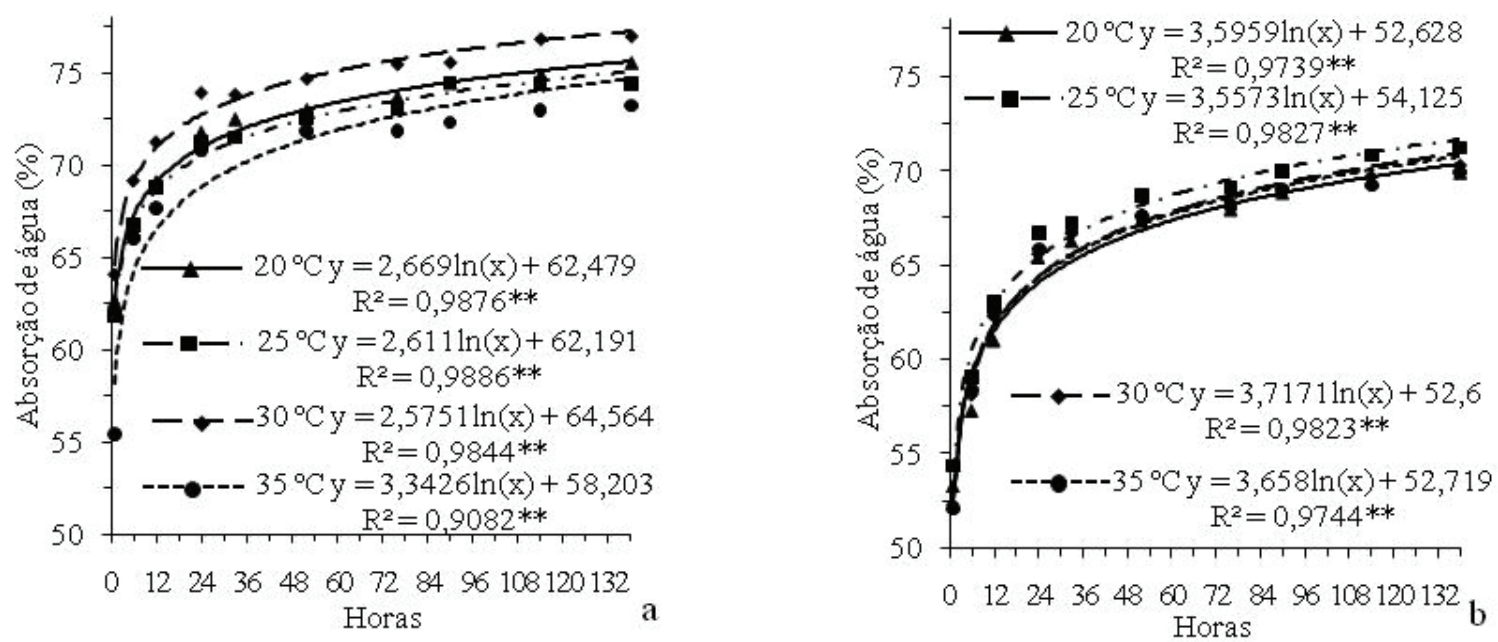

Figura 1. Curvas de absorção de água de sementes de Dyckia goehringii Gross \& Rauh (Bromeliaceae), submetidas às temperaturas $20^{\circ} \mathrm{C}, 25^{\circ} \mathrm{C}, 30^{\circ} \mathrm{C}$ e $35^{\circ} \mathrm{C}$. a) Curvas de absorção de água em sementes pequenas ( $\left.>1,00 \mathrm{~mm} \mathrm{e} \leq 3,76 \mathrm{~mm}\right)$. b) Curvas de absorção de água em sementes grandes $(>3,76 \mathrm{~mm}$ e $\leq 5,90 \mathrm{~mm})$. ** Resultados significativos a $1 \%$ de probabilidade, pelo teste F, na análise de regressão (Goiânia, GO, 2005). 
incrementos na germinação entre 6 e 13 dias, a partir do início da germinação. Além disso, o lento crescimento das plântulas, as quais não ultrapassaram 1,56 cm de comprimento médio total, ao final da avaliação, indica lenta absorção de água para o crescimento inicial.

Não foram observadas grandes variações nos teores de água absorvidos pelas sementes, nas diferentes temperaturas, mas verificou-se que as sementes pequenas absorveram, proporcionalmente, mais água do que as sementes grandes (Figuras 1a e 1b), sendo salientado, por Borges \& Rena (1993), que isto ocorre como resultado das características externas do tegumento. Estes autores consideram a existência de uma relação inversamente proporcional entre o tamanho e a absorção de água. Souza et al. (1996) verificaram que sementes maiores de Calopogonium mucunoides Desv. apresentaram absorção de água mais lenta e melhor qualidade fisiológica, corroborando os resultados observados no presente trabalho.

As sementes pequenas, sob $30^{\circ} \mathrm{C}$, tenderam a absorver mais água (Figura 1a), mas a maior capacidade de germinação foi observada a $25^{\circ} \mathrm{C}$ (Figura 2a). Para as sementes grandes, as curvas de embebição foram bastante semelhantes (Figura 1b).

A germinação das sementes de D. goehringii é do tipo criptocotiledonar-epigeal, ou seja, as sementes contendo o cotilédone ficam acima da superfície do solo. Neste tipo de germinação, os cotilédones podem ser fonte de reservas e/ou drená-las do endosperma, para o crescimento embrionário (Mayer \& Poljakoff-Mayber 1963, Duarte 2001). Durante a germinação das Bromeliaceae, a parte inferior dos cotilédones alonga-se e empurra a radícula para fora da semente, mantendo a plúmula no interior da bainha cotiledonar, enquanto a parte superior mantém-se inserida no endosperma, como um órgão de absorção. Mais especificamente na subfamília Pitcairnioideae, as sementes mantêm-se unidas aos cotilédones por pouco tempo (Smith \& Downs 1974).

A germinação sobre papel de sementes intactas de $D$. goehringii, dos lotes de sementes pequenas e grandes, ocorreu em todas as temperaturas testadas (Figuras $2 \mathrm{a}$ e $2 \mathrm{~b}$ ), fato que pode ser favorável ao estabelecimento de condições naturais, conforme discutem Vieira et al. (2007), para a geminação de Dyckia tuberosa entre $15^{\circ} \mathrm{C}$ e $40^{\circ} \mathrm{C}$, pois as espécies podem germinar em uma ampla faixa de temperatura. Mas, ao se padronizar o teste de germinação na faixa ótima de temperatura para a espécie, torna-se possível reproduzi-lo e compará-lo (Brasil 1992, Marcos Filho 2005).

Para a maioria das espécies de bromélias, as temperaturas entre $25^{\circ} \mathrm{C}$ e $30^{\circ} \mathrm{C}$ são favoráveis ao processo de germinação, levando de 7 a 28 dias, a $25^{\circ} \mathrm{C}$ (Smith \& Downs 1974). Estes resultados, assim como os observados no presente estudo, assemelham-se àqueles obtidos por Pinheiro \& Borghetti (2003), para bromélias da restinga.

A aplicação de teste de médias (SNK) aos dados do $17^{\circ}$ dia após a semeadura (DAS) permitiu constatar que a germinação de sementes pequenas foi superior $(\mathrm{p} \leq 0,05)$ a $25^{\circ} \mathrm{C}$ (Figura $2 \mathrm{a}$ ) e que sementes grandes germinaram melhor e mais rapidamente a

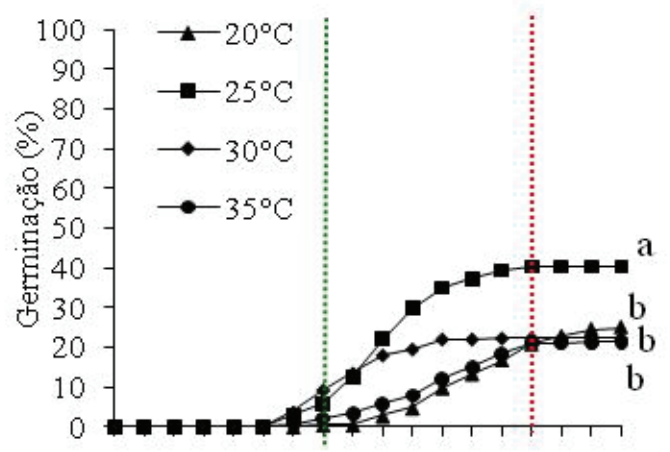

01234567891011121314151617 Dias após a semeadura

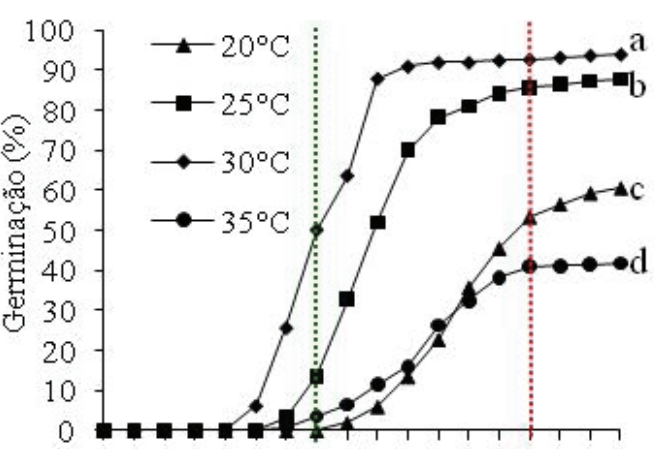

01234567891011121314151617 Dias após a semeadura

Figura 2. Comportamento germinativo das sementes de Dyckia goehringii Gross \& Rauh (Bromeliaceae), ao longo de 17 dias, sob temperaturas de $20^{\circ} \mathrm{C}, 25^{\circ} \mathrm{C}, 30^{\circ} \mathrm{C} \mathrm{e} 35^{\circ} \mathrm{C}$. a) Percentagem de germinação de sementes pequenas $(>1,00 \mathrm{~mm} \mathrm{e} \leq 3,76 \mathrm{~mm})$. b) Percentagem de germinação de sementes grandes (>3,76 $\mathrm{mm} \mathrm{e} \leq 5,90 \mathrm{~mm}$ ). Médias seguidas por letras distintas, na última avaliação (17 DAS), diferem entre si, a 5\% de probabilidade, pelo teste SNK (Goiânia, GO, 2005). 
$30^{\circ} \mathrm{C}(94,00 \%)$ (Figura 2b). Muraro (2006) verificou baixa germinação de Vriesea incurvata, em condições naturais, com máxima germinação de $40,5 \%$, com a temperatura média do ar variando entre $15^{\circ} \mathrm{C}$ e $30^{\circ} \mathrm{C}$, mantendo-se acima de $20^{\circ} \mathrm{C}$, na maioria do período.

A germinação das sementes de D. goehringii iniciou-se aos quatro dias após a semeadura (DAS) e a estabilização deu-se aos 14 DAS, para a maioria das temperaturas testadas em sementes pequenas, com exceção da temperatura de $20^{\circ} \mathrm{C}$, para a qual não foi detectada a estabilização até o final do experimento (Figura 2a). Para as sementes grandes, a melhor temperatura foi $30^{\circ} \mathrm{C}$, com início da germinação aos 4 DAS e estabilização entre o $8^{\circ}$ e $10^{\circ}$ DAS. Vieira et al. (2007) verificaram que, entre $18^{\circ} \mathrm{C}$ e $20^{\circ} \mathrm{C}$, as sementes de Dyckia tuberosa germinam entre $15 \mathrm{e}$ 20 dias, apesar de a faixa ótima de germinação para esta espécie estar entre $20^{\circ} \mathrm{C}$ e $40^{\circ} \mathrm{C}$. Para Dyckia dystachia, a estabilização da germinação ocorre ao final da primeira semana do teste de germinação, conduzido em condições ambientais, com temperaturas variando entre $21^{\circ} \mathrm{C}$ e $30^{\circ} \mathrm{C}$ (Wiesbauer et al. 2007).

Houve um pequeno incremento na germinação das sementes grandes, após o $14^{\circ} \mathrm{DAS}$, quando foram colocadas em germinador, a $30^{\circ} \mathrm{C}$, sendo que esta diferença não ultrapassou $0,75 \%$, até o $17^{\circ} \mathrm{DAS}$ (Figura 2b). Ressalta-se que, para a realização de testes de germinação, o processo germinativo deve ser regular, rápido e completo, para a maioria das amostras, e conduzido de forma a oferecer condições ótimas para as sementes (Brasil 1992). Por razões práticas e por permitir a distinção entre lotes de diferentes qualidades fisiológicas, futuros estudos e rotinas laboratoriais poderão adotar 14 DAS para a avaliação final da germinação de $D$. goehringii.
A avaliação adicional da primeira contagem, aos 7 DAS, também poderá ser utilizada, pois mostrou-se sensível $(\mathrm{p} \leq 0,01)$ às diferenças de germinação dos tratamentos testados (Tabela 2). Valentini \& Piña-Rodrigues (1995) consideram vantajosa a padronização da época de avaliação da primeira contagem e sua realização conjunta com o teste de germinação, na avaliação do vigor das sementes florestais.

As sementes pequenas apresentaram capacidade germinativa cerca de duas a quatro vezes menor do que as sementes grandes, tendo sido obtida a maior percentagem $(40,25 \%)$ quando a temperatura utilizada foi de $25^{\circ} \mathrm{C}$ (Figura 2a). Carvalho \& Nakagawa (2000) ressaltam que nem sempre o tamanho da semente afeta a taxa e a velocidade de germinação, porém, geralmente, influencia o vigor das plântulas resultantes.

$O$ vigor das sementes e das plântulas de D. goehringii foi afetado pela temperatura e pelo tamanho das sementes, às temperaturas de $20^{\circ} \mathrm{C}$ e $30^{\circ} \mathrm{C}$. Para as sementes grandes e pequenas, houve diferenças significativamente superiores para a germinação das sementes aos sete dias (primeira contagem), a $30^{\circ} \mathrm{C}$ (Tabela 2). Para todas as variáveis de vigor analisadas, os melhores resultados foram obtidos para sementes grandes, submetidas à temperatura de $30^{\circ} \mathrm{C}$, indicando que sementes com maior quantidade de reservas podem apresentar melhor comportamento, em relação à germinação e vigor. Possivelmente, as plântulas foram mais vigorosas devido à aceleração no metabolismo respiratório das reservas (Melo et al. 2004), durante o processo germinativo. De forma semelhante, sementes maiores de Eugenia dysenterica (Duarte et al. 2006) originaram plântulas mais vigorosas.

Tabela 2. Vigor de sementes e de plântulas de Dyckia goehringii Gross \& Rauh (Bromeliaceae), obtidas de sementes pequenas $(>1,00 \mathrm{~mm} \mathrm{e} \leq 3,76 \mathrm{~mm})$ e grandes ( $>3,76 \mathrm{~mm} \mathrm{e} \leq 5,90 \mathrm{~mm})$, germinadas sob diferentes temperaturas (Goiânia, GO, 2005).

\begin{tabular}{lcrrrr}
\hline \multirow{2}{*}{ Variável } & \multirow{2}{*}{ Lote* } & \multicolumn{4}{c}{ Temperatura** } \\
\cline { 3 - 6 } & & $20^{\circ} \mathrm{C}$ & $25^{\circ} \mathrm{C}$ & $30^{\circ} \mathrm{C}$ & $35^{\circ} \mathrm{C}$ \\
\hline \multirow{2}{*}{ Germinação na primeira contagem (\%) } & 1 & $0,50 \mathrm{Ac}$ & $5,75 \mathrm{Bb}$ & $9,25 \mathrm{Ba}$ & $2,00 \mathrm{Abc}$ \\
& 2 & $0,00 \mathrm{Ad}$ & $13,50 \mathrm{Ab}$ & $50,25 \mathrm{Aa}$ & $3,50 \mathrm{Ac}$ \\
\hline \multirow{2}{*}{ Índice de velocidade de germinação } & 1 & $10,20 \mathrm{Bb}$ & $28,01 \mathrm{Ba}$ & $18,95 \mathrm{Bb}$ & $11,41 \mathrm{Bb}$ \\
& 2 & $25,64 \mathrm{Ac}$ & $62,20 \mathrm{Ab}$ & $86,94 \mathrm{Aa}$ & $23,08 \mathrm{Ad}$ \\
\hline \multirow{2}{*}{ Comprimento da parte aérea da plântula $(\mathrm{cm})$} & 1 & $0,29 \mathrm{Ad}$ & $0,87 \mathrm{Ab}$ & $1,11 \mathrm{Ba}$ & $0,63 \mathrm{Ac}$ \\
\multirow{2}{*}{ Comprimento da raiz da plântula (cm) } & 1 & $0,31 \mathrm{Ad}$ & $0,85 \mathrm{Ab}$ & $1,19 \mathrm{Aa}$ & $0,56 \mathrm{Bc}$ \\
\hline \multirow{2}{*}{ Massa da matéria fresca da plântula (mg) } & 2 & $0,14 \mathrm{Ac}$ & $0,26 \mathrm{Aa}$ & $0,28 \mathrm{Ba}$ & $0,23 \mathrm{Bb}$ \\
& 2 & $6,00 \mathrm{Bc}$ & $11,20 \mathrm{Bb}$ & $15,70 \mathrm{Ba}$ & $0,27 \mathrm{Ab}$ \\
\hline
\end{tabular}

* $1=$ sementes pequenas; $2=$ sementes grandes. ** Médias seguidas por letras distintas, maiúsculas, nas colunas, e minúsculas, nas linhas, diferem entre si, a $5 \%$ de probabilidade, pelo teste SNK. 
A velocidade de germinação é um dos testes mais antigos utilizados para avaliação do vigor de sementes, podendo discriminar lotes de sementes que apresentam germinação similar, sendo considerados mais vigorosos aqueles que demonstram germinação mais rápida (Nakagawa 1994). O vigor, representado pelo índice de velocidade de germinação (IVG), pode ser determinante no estabelecimento das plântulas no campo. Hernández et al. (1999) citam o exemplo de Tillandsia guatemalensis, que apresentou germinação em condições laboratoriais acima de $93 \%$, porém, em condições naturais, com a ocorrência de chuvas torrenciais, muitas plântulas foram arrastadas antes de se fixarem ao substrato, levando a uma redução de mais da metade das plantas jovens.

Durante a realização do teste de germinação sob temperatura de $35^{\circ} \mathrm{C}$, foi observada a presença de plântulas albinas, as quais apresentaram desenvolvimento inicial similar às demais, definhando, rapidamente, após determinado período. Apesar de as plântulas albinas apresentarem-se com baixa frequência, demonstram que as sementes das quais se originaram sofreram algum grau de deterioração, sendo descrito por Marcos Filho (2005) e por Peske et al. (2006) o aumento do número de plântulas anormais, à medida que a deterioração aumenta. Sugere-se a realização de estudos específicos para compreender as causas do albinismo nas plântulas de $D$. goheringii.

O presente estudo é uma contribuição para o conhecimento das bromélias do Cerrado, estabelecendo parâmetros iniciais para a condução de testes de germinação e análise de vigor em sementes de D. goehringii, além de ressaltar aspectos relacionados à embebição e à germinação, sob condições favoráveis de umidade e temperatura. Será necessária, ainda, a realização de estudos específicos para a identificação de plântulas vigorosas e normais, características, estas, que podem garantir a sua sobrevivência, em condições ambientais naturais e/ou de cultivo.

\section{CONCLUSÕES}

1. As sementes de D. goehringii não apresentam impedimento para absorção de água, sendo influenciadas, principalmente, pelo tamanho das sementes.

2. Sementes grandes apresentam maior germinação e vigor, originando plântulas mais vigorosas do que as sementes pequenas e expressando melhor o seu potencial fisiológico à temperatura de $30^{\circ} \mathrm{C}$.
3. As avaliações do teste de germinação devem ser realizadas ao sétimo e décimo quarto dias após a semeadura.

\section{AGRADECIMENTOS}

Ao Conselho Nacional de Desenvolvimento Científico e Tecnológico (CNPq), pela concessão de bolsa ao primeiro autor, e aos professores e técnicos da Escola de Agronomia e Engenharia de Alimentos da Universidade Federal de Goiás, pelo auxílio e apoio.

\section{REFERÊNCIAS}

ABREU, M. E. P.; GARCIA, Q. S. Efeito da luz e da temperatura na germinação de sementes de quatro espécies de Xyris L. ocorrentes na Serra do Cipó, MG, Brasil. Acta Botanica Brasilica, São Paulo, v. 19, n. 1, p. 149-154, 2005.

BEWLEY, D.; BLACK, M. Seeds: physiology of development and germination. New York: Plenum Press, 1986.

BORGES, E. E. L.; RENA, A. B. Geminação de sementes. In: AGUIAR, I. B.; PINNA-RODRIGUES, F. C. M.; FLIGLIOLIA, M. B. (Coords.). Sementes florestais tropicais. Brasília, DF: Abrates, 1993. p. 83-135.

BRASIL. Ministério da Agricultura e Reforma Agrária. Regras para análise de sementes. Brasília, DF: SNDA/ DNDV/CLAV, 1992.

BRAUM, P. J.; PEREIRA, E. E. Zur klärung der herkunft von Dyckia goehringii E. Gross \& Rauh. Die Bromelie, Kirchberg, v. 3, n. 1, p. 64-65, 2004.

CARVALHO, N. M.; NAKAGAWA, J. Sementes: ciência, tecnologia e produção. Jaboticabal: Funep, 2000.

CASTRO, R. D.; BRADFORD, K. J.; HILHORST, H. W. M. Desenvolvimento de sementes e conteúdo de água. In: FERREIRA, A. G.; BORGHETTI, F. (Orgs.). Germinação: do básico ao aplicado. Porto Alegre: Artmed, 2004. p. 51-67.

CROMARTY, A. S.; ELLIS, R. H.; ROBERTS, E. H. Design of seed storage facilities for genetic conservation. Rome: IBPGR, 1985.

DUARTE, E. F. Anatomia, maturação e dormência de sementes de Xylopia aromatica (Lam.) Mart. (Annonaceae). 2001. 62 f. Dissertação (Mestrado em Botânica)-Instituto de Biociências, Universidade Estadual Paulista "Júlio de Mesquita Filho", Botucatu, 2001.

DUARTE, E. F. Caracterização, qualidade fisiológica de sementes e crescimento inicial de Dyckia goehringii Gross \& Rauh, bromélia nativa do Cerrado. 2007. 200 f. Tese (Doutorado em Produção Vegetal)-Universidade Federal de Goiás, Goiânia, 2007. 
DUARTE, E. F. et al. Germinação e vigor de sementes de cagaita (Eugenia dysenterica MART. ex DC.) em função do tamanho e tipo de coleta. Pesquisa Agropecuária Tropical, Goiânia, v. 36, n. 3, p. 173-179, 2006.

FELFILI, J. M. et al. Potencial econômico da biodiversidade do Cerrado: estádio atual e possibilidades de manejo sustentável dos recursos da flora. In: AGUIAR, L. M. S.; CAMARGO, A. J. A. Cerrado: ecologia e caracterização. Planaltina: Embrapa Cerrados, 2004. p. 177-220.

FENNER, M. Seed ecology. London: Chapman \& Hall, 1993.

FRAZÃO, D. A. C. et al. Tamanho da semente de guaraná e sua influência na emergência e no vigor. Revista Brasileira de Sementes, Brasília, DF, v. 5, n. 1, p. 81-91, 1983.

GOMES, V.; FERNANDES, G. W. Germinação de aquênios de Baccharis dracunlifolia D. C. (Asteraceae). Acta Botanica Brasilica, São Paulo, v. 16, n. 4, p. 421427, 2002.

HERNÁNDEZ, J. C. C. et al. The influence of humidity, nutrients and light on the establishment of the epiphytic bromeliad Tillandsia guatemalensis in the highlands of Chiapas, Mexico. Revista de Biologia Tropical, San José, v. 47, n. 4, p. 1-14, 1999.

LABOURIAU, L. G. A germinação das sementes. Washington: Secretaria Geral da Organização dos Estados Americanos, 1983.

LEME, E. M. C.; MARIGO, L. C. Bromélias na natureza. Rio de Janeiro: Marigo Comunicação Visual, 1993.

MAGUIRE, J. D. Speed of germination-aid in selection and evaluation for seedling emergence and vigor. Crop Science, Madison, v. 2, n. 2, p. 176-177, 1962.

MARCOS FILHO, J. Fisiologia de sementes de plantas cultivadas. Piracicaba: Fealq, 2005.

MAYER, A. M.; POLJAKOFF-MAYBER, A. The germination of the seeds. Oxford: Pergamon Press, 1963.

MELO, F. P. L. et al. Recrutamento e estabelecimento de plântulas. In: FERREIRA, A. G.; BORGHETTI, F. (Orgs.). Germinação: do básico ao aplicado. Porto Alegre: Artmed, 2004. p. 237-250.

MENESCAL, R. Reprodução de bromélias por sementes. Bromélia, Rio de Janeiro, v. 1, n. 4, p. 8-10, 1994.

MURARO, D. Germinação em substratos alternativos ao xaxim e aspectos fenológicos e reprodutivos de Vriesea incurvata Gaudich.: subsídios à produção sustentável. 2006. 66 f. Dissertação (Mestrado em Produção Vegetal) Setor de Ciências Agrárias, Universidade Federal do Paraná, Curitiba, 2006.

NAKAGAWA, J. Testes de vigor baseados na avaliação das plântulas. In: VIEIRA, R. D.; CARVALHO, N. M. Testes de vigor em sementes. Jaboticabal: Funep, 1994. p. 49-102.

PEREIRA, T. S. Bromelioideae (Bromeliaceae): morfologia do desenvolvimento pós-seminal de algumas espécies. Arquivos do Jardim Botânico do Rio de Janeiro, Rio de Janeiro, v. 29, n.1, p. 115-154, 1988.

PESKE, S. T.; LUCCA FILHO, O. A.; BARROS, A. C. S. A. Sementes: fundamentos científicos e tecnológicos. Pelotas: UFPel, 2006.

PIMENTEL-GOMES, F. (Ed.). Curso de estatística experimental. Piracicaba: ESALQ/USP, 2000.

PINHEIRO, F.; BORGHETTI, F. Light and temperature requirements for germination of seeds of Aechmea nudicaulis (L.) Griesebach and Streptocalyx floribundus (Martius ex Schultes F.) Mez (Bromeliaceae). Acta Botanica Brasilica, São Paulo, v. 17, n. 1, p. 27-35, 2003.

POLLOCK, B. M.; ROOS, E. E. Seed and seedling vigor. In: KOZLOWSKI, T. T. (Ed.). Seed biology. New York: Academic Press, 1972. p. 313-377.

POMPELLI, M. F. Germinação de Dyckia encholirioides var. enchorilirioides (Bromeliaceae-Pticairnioideae). Floresta e Ambiente, Seropédica, v. 13, n. 1, p. 1-9, 2006.

SAMPAIO, I. B. M. Estatística aplicada à experimentação animal. Belo Horizonte: Fundação de Estudos e Pesquisa em Medicina Veterinária e Zootecnia, 1998.

SANTANA, D. G.; RANAL, M. A. Análise da germinação: um enfoque estatístico. Brasília, DF: Ed. da UnB, 2004.

SILVA, E. M. N. Determinação de umidade. In: PIÑARODRIGUES, F. C. M. (Coord.). Manual de análise de sementes florestais. Campinas: Fundação Cargill, 1988. p. 60-69.

SIQUEIRA FILHO, J. A.; TABARELLI, M. Bromeliads species of the Atlantic forest of north-east Brazil: losses of critical populations of endemic species. Oryx, Cambridge, v. 40 , n. 2 , p. 1-7, 2006.

SMITH, L. B.; DOWNS, R. J. Flora neotropica: Pitcairnioideae (Bromeliaceae). New York: OFN-Halfner Press, 1974.

SOUZA, F. H. D.; MARCOS FILHO, J.; NOGUEIRA, M. C. S. Características físicas das sementes de Calopogonium mucunoides Desv. associadas à qualidade fisiológica e ao padrão de absorção de água: I. Tamanho. Revista Brasileira de Sementes, Londrina, v. 18, n. 1, p. 33-40, 1996.

VAlENTINI, S. R.; PIÑA-RODRIGUES, F. C. M. Aplicação do teste de vigor em sementes. In: SILVA, A.; PIÑA-RODRIGUES, F. C. M.; FIGLIOLIA, M. B. (Coords.). Manual técnico de sementes florestais. IF-Série Registros, São Paulo, v. 14, n. 1, p. 75-84, 1995.

VIEIRA, D. C. M.; SOCOLOWSKI, F.; TAKAKI, M. Germinação de sementes de Dyckia tuberosa (Vell.) Beer (Bromeliaceae) sob diferentes temperaturas em luz e escuro. Revista Brasileira de Botânica, São Paulo, v. 30, n. 12, p. 183-188, 2007.

WIESBAUER, M. B. et al. Influência da luz e inundação na germinação de Dyckia distachya Hassler, uma bromélia em vias de extinção. Revista Brasileira de Biociências, Porto Alegre, v. 5, supl. 1, p. 717-719, 2007. 